\title{
Insecurity and Self-Acceptance Portrayed in Samsung Galaxy A8 Advertisement "Lets You Be You": A Multimodal Analysis
}

\author{
Stefanus Fernando \\ English Department, Faculty of Languages and Literature, Petra Christian University, Siwalankerto 121 - \\ 131, Surabaya 60236, INDONESIA \\ Email: stefrndoo@gmail.com
}

\begin{abstract}
This study analyzed the issue of insecurity and self-acceptance portrayed in Samsung Galaxy A8 advertisement entitled "Lets You Be You". The main theory for this study is the theory of multimodal discourse analysis by Paltridge (2012) and the theory of body language by Pease (2004) as the supporting theory. Qualitative approach is applied because this study involves the interpretation of both verbal and nonverbal data. The findings showed how the issue of insecurity is reflected through the reaction of the participants in the video before and after receiving a compliment. Furthermore, the construction of the changing process from insecurity to self-acceptance can be seen from the genuine reaction of the compliment, as well as the change of facial expression throughout the video.
\end{abstract}

Key words: Insecurity, Self-acceptance, Multimodal Discourse Analysis, Advertisement, Samsung

\section{INTRODUCTION}

Advertisement plays an important role in running a business, it has become an important business tool for many companies because it enables companies around the world to reach a bigger audience in promoting their products. Harris $(2004$, p.98) states that advertisements try to alter or change the reality of those who see it. Consumers may have a certain view of a product, such as that they do not intent to buy the product. Here advertisements play a role in creating consumers' feeling that they need to purchase a particular product which they have not really thought of purchasing before. In addition, many companies use advertisements to boost their image. This is important because in today's world, people pay close attention to the image of a company in order to trust them. Some advertisements are designed to change consumers' perspective on the companies advertised, while some are created to persuade consumers to purchase their products. In this way, advertisements are used for influencing the consumers' emotion, as advertisement, according to Harris (2004, p.99), is the best step to change their belief on the company, and finally, their behavior.

A good example can be seen from some Samsung's video advertisements. One of their advertisements that attracts the writer's attention is Samsung Galaxy A8 advertisement. This advertisement, entitled as "Galaxy A8: Official Digital Film - Lets You Be You," was uploaded in Samsung's official YouTube channel on January 3 2018. In this video, Samsung employs Shea Vaughan-Gabor, also known as Shea Glover, a youtuber and filmmaker, to create the video. This video advertisement itself is the recreation of Glover's 2015 film titled "People react to being called beautiful". Samsung's choice to employ Shea is an excellent decision because Samsung is tapping into "the crave of authenticity" in Generation Z (ThinkMarketing, January 14, 2018). Therefore, Samsung created this advertisement campaign in order to fulfil the craving. Shea Glover, who appears on screen, as well as the co-director, is seen telling strangers that they are beautiful just as they appear.

Samsung Galaxy A8 advertisement is interesting because, first of all, this advertisement 
explores two issues that are faced by many people across the globe, that is, insecurity, a lack of confidence within oneself, and self-acceptance. Secondly, Samsung indirectly advertises the smartphone. Instead of directly persuading people to buy their product, Samsung focuses on the issue of insecurity and self-acceptance through a social experiment, in which Samsung Galaxy A8 is used as the tool to record the reaction of the participants. By doing so, Samsung indirectly markets its smartphone, telling the viewers that Samsung Galaxy A8 helps them to capture their true beauty.

Insecurity and self-acceptance are two sensitive topics, in which not many people are comfortable talking about. Nowadays, people tend to feel insecure on how they look, they constantly feel like they have to look more and more like other people which they think are better than their true selves. The insecurity leads to people unable to accept themselves, because people often talk about how they look. As a result, this issue is rather unpleasant for general discussion, or worse, for a videotaped interview. Samsung took the challenge and addressed the issue in a form of advertisement, showing that they are not alone and it is okay to be themselves because each person is beautiful in their own way. Because of the two issues that Samsung decides to address, the writer is interested in analyzing its advertisement, that is, Samsung Galaxy A8 advertisement titled "Lets You be You".

In addressing the issue of insecurity and self-acceptance in the "Lets You Be You" video, Samsung and Glover try to create an emotional advertisement. The advertisement starts with Glover setting up her Galaxy A8 smartphone on a tripod, preparing to take pictures of random strangers as the part of the social experiment. In the video, she interviews 8 (eight) men and 14 (fourteen) women, each with their own appearance. The depiction of the process of interview of the advertisement contains both verbal and visual expressions; tagline, colors, composition, and facial expressions. In analyzing all of the components, Multimodal approach as suggested by Paltridge (2012) is useful.

The writer chose to use Multimodal approach in this research because Multimodal Discourse Analysis is an effective theory for analyzing advertisement which he has selected. Paltridge (2012, p.170) states that Multimodal Discourse Analysis focuses on how meaning is constructed through the combination of words in modes of communication such as pictures, film, video, images, and sound. In this research, the writer decided to use video advertisement, for it is the most common marketing tool in the present. Specifically, the writer would like to focus on how words are used in the video, along with the images and sound in their ability to create meanings.

In conducting this research, the writer used the theory of Multimodal Discourse Analysis by Brian Paltridge (2012) to find out how the issue of insecurity is reflected in Samsung's video advertisement, and how the changing process of insecurity to self-acceptance is constructed in the advertisement. The writer also used the theory of body language by Allan and Barbara Pease (2004) in order to support the main theory used in his research.

\section{Multimodal Discourse Analysis}

As Paltridge (2012, p. 170) states in his book, Multimodal Discourse Analysis focuses on how meaning is constructed through the combination of words, along with pictures, film, video, images, and sound in modes of communication in order to create meaning. Multimodal Discourse Analysis is used to analyze printed and digital media such as, newspaper ads, brochures, web pages, films, and television programs. This theory explores how multimodal texts and semiotic tools contribute to the creation of meaning, as quoting Halliday and Hasan (1985), Davies writes, "a text is a semiotic resource embodying discourse and creating new meanings" (2011, p. 230). According to O'Halloran, semiotic resources refer to "the resources (or modes) (e.g. language, image, music, gesture and architecture), which integrate across 
sensory modalities (e.g. visual, auditory, tactile, olfactory, gustatory, kinesthetic) in multimodal texts, discourses and events" (2011, p. 121). In this research, I limit the semiotic resources into two resources. First are words which are seen from the verbal responses of the participants, and second images which are the visible impression of the participants that are captured by the camera. In this case, their facial expression and body language. In this research I would like to focus on the reaction of the people that are interviewed, and that is the reason why I limit the semiotic resources into two because words and images are the most dominant resources in the video and are able to contribute in the analysis.

\section{Smile and Laughter}

Allan and Barbara Pease state that a sincere or natural smile involves both wrinkle in both lips and beside the eyes. Fake smile, on the other hand, only involves the smiling lips (2004, p.67). Furthermore, natural smiles are produced by the unconscious brain, which means that they are automatic. When someone feel a great pleasure, the signal passes through the part of the brain which processes emotion, then making his or her mouth muscles move, raising the cheeks and eyes crease, and dropping the eyebrows slightly (2004, p.68). In addition, smile and laughter also a submissive signal, both are universally considered as a sign that a person is happy. Smile also shows other people that the person thinks the other speaker as non-threatening and also accepts them on a personal level. Lack of smile, on the other hand, shows the sign of dominance, Vladimir Putin is one example of a figure who rarely seen smiling. This simply means that he does not want to be seen as submissive (2004, p.69-70). The theory of smile and laughter is relevant in this research because it is the major reaction seen from the respondents in the video, specifically after they are called beautiful by the interviewer.

\section{Eye Signals}

People spend most of their face-to-face conversation looking at the other speaker's face, so that is why eyes play a major role in reading the person's attitude and thoughts at that time (Allan \& Barbara Pease, 2004, p.165). There are two notable eye signals in the video; Eyebrow Flash and Sideway Glance. Eyebrow Flash is a universal gesture that has been used since the ancient times, indicating that this gesture is innate to human (Allan \& Barbara Pease, 2004, p.171). Rising the eyebrows indicates that the person is surprised, scared, or even both. Lowering the eyebrows, on the other hand, shows that the person is showing dominance or aggression towards the other speaker. When a person lowers their eyebrows, it also indicates that the person feels uncomfortable or shows annoyance (Allan \& Barbara Pease, 2004, p.171-172). Sideway Glance is used to indicate either signs of interest or hostility. When the sideway glance is combined with slightly raised eyebrows or a smile, it communicates interest. However, if it is combined with lowered eyebrows, furrowed brows, or down-turned mouth, it shows a suspicious, hostile, or critical attitude (Allan \& Barbara Pease, 2004, p.179).

\section{METHOD}

This research is conducted using qualitative approach. This approach is used because it deals with both verbal and visual expressions in the advertisement of Samsung Galaxy A8, in articulating how insecurity and self-acceptance are portrayed. Qualitative approach is suitable in this research because according to Schreier the approach deals with interpretation of the data, both verbal and visual (Schreier, 2012, pp. 2-3).

The source of data for this research is a video advertisement of Samsung, specifically an advertisement of their smartphone, Galaxy A8 "Lets You be You" which is uploaded on Samsung's official YouTube channel (https://www.youtube.com/channel/UCWwgaK7x0_FR1goeSRazfsQ) on January 3 2018. The 
video advertisement is one minute and fifty seconds long, and it uses English language for the narration, as well as the video-taped interview. The instrument of this research is the writer who collected the data from the source mentioned earlier, and he was also the one who analyzed the data as well.

The data for this research is the verbal and nonverbal expressions presented in the video advertisement. The verbal data was acquired through transcribing the dialogue in the video, and the nonverbal data was acquired through taking screenshots of the facial expressions contained in the video. Then, the writer organized the data in a form of table that later help him in writing the analysis in the fourth chapter.

Before analyzing the data, the writer proceeded to watch the video several times to understand the advertisement itself. After watching the ads, he then proceeded to transcribe the video in terms of dialogues, actions, and texts that are present in the video. Next, he took screenshots of the scenes that are necessary for the nonverbal analysis. After he obtained the data needed, he compiled it in a form of table. The table contains the time frames of the video, screenshots of the scenes, visual expression, verbal expression, and the implication of each scene.

After the writer finished compiling the data in the table, he proceeded to analyze the scenes which are divided into two major points. The first point is the analysis of the reflection of insecurity in the video advertisement and the second point covers the analysis of the changing process from insecurity to self-acceptance that are constructed in the advertisement.

\section{FINDINGS AND DISCUSSION}

In the findings and discussion, the writer covered the findings of his analysis on the data to answer the research questions that he set, as well as to reach the purpose of the study which is to find out how Multimodal Discourse Analysis is used to find out how the issue of insecurity and self-acceptance are portrayed in the advertisement through the verbal and non-verbal expressions that are present in the video advertisement. The writer divided this section into two major parts. The first part covers the reflection of insecurity in the video advertisement. The second part covers the construction of the changing process from insecurity to self-acceptance in the advertisement.

\section{Reflection of Insecurity in the Video Advertisement}

Since the first research question of this research is to find out how the issue of insecurity is reflected in the video, the writer began the analysis by finding out how verbal and non-verbal expressions are able to portray the issue of insecurity in the scenes of the advertisement.

Facial expression plays an important role in the creation of meaning in this advertisement. Which is exemplified in one of the scenes. In the first scene, a woman is seen standing at the center of the scene and looking straight to the camera. The woman in this scene is seen showing a neutral expression or a straight face while looking at the camera. Her facial expression expresses ambiguity, how the woman feels in this scene is unknown. In the picture, she is simply seen with a straight face. However, when looking at the context of the video, the woman's expression gives a different meaning to the neutral expression. Since the woman is a participant of a videotaped social experiment, her neutral expression is generated in order to hide the nervous feeling of being interviewed on camera. The feeling of insecurity is also reinforced by the colors used in this scene, which create a gloomy atmosphere. As Paltridge (2012) states that meaning is constructed through the combination of words, pictures, film, video, images, and sound, the gloomy atmosphere is created through the color blue and purple, combined with a low lighting around the woman. The combination of color and lighting gives a 
darker shadow on her right side. The darker shadow exposes the woman's emotion which is hidden from other people's view. In this scene, the semiotic resources, in the form of colors, images, lighting, and words, signify the insecurity the woman feels.

Another nonverbal expression that is involved in the creation of meaning is smile. This scene starts with a woman looking straight to the camera. The woman is seen with a neutral expression for a few seconds before slowly forming a smile. This scene takes place at the very beginning of the video, so the woman in this scene is still listening to the interviewer's explanation of the project. She later forms a nervous, which is generated because she is being interviewed in a public place by a stranger. Not to mention that the interview is videotaped and has a chance to be publicized to people across the globe. Quoting Jewitt, Paltridge writes that "Images, gaze and posture, thus, do not just support meaning, they each contribute to meaning" (2012, p.171). Paltridge's opinion supports my argument that the woman's facial expression, her gaze, her eye contact, and her nervous smile, all of which serve as the semiotic resources that produce meaning, reflect her insecurity.

Laughter is also one of nonverbal expressions that is present in the advertisement. In this scene, the woman is replying to the interviewer, the woman says laughingly "Okay, so that's me." Her laughter is triggered right after the interviewer explains that the interviewer's project is to take pictures that she finds beautiful. Her laughter may imply that she does not think she is beautiful. In this way, her laughter serves as semiotic resource that shows her disagreement with the interviewer regarding the latter's opinion that she is beautiful. Her laugh may be her means to create a "happy zone" even though she does not think that it is true, as stated by Pease that "people who laugh or smile, even when they don't feel especially happy, make part of the "happy zone"” (2004, p.80). Furthermore, there are a few seconds of silence after her first response where the woman seemed to be hesitant about her own statement before. This time, she adds "So, okay, I don't know, I don't know how to take pictures like that.". The woman is seen adjusting her hair and avoiding eye contact for a brief moment while giving her second response to the interviewer with an awkward smile on her face. Her response shows how the woman doubts herself. The response "I don't know, I don't know how to take pictures like that." shows how the woman is clearly doubting her own appearance, as well as her inability to take pictures of herself that shows her beauty. Her awkwardness and hesitation, as reflected by her facial expression where she avoids eye contact reveal her insecurity, as Paltridge says that the avoidance of eye contact shows lack of confidence (2012, p.172). In this case, the woman is not confident to admit that she is beautiful.

Eye contact of a person in the shot is able to reveal his or her emotion at the time. This is reflected in the next scene. The woman in this scene can be seen not looking straight at the camera, and avoiding eye contact with the interviewer as well. She is also seen with a down turned mouth as she gives her response before looking at the direction of the camera and the interviewer with a sad expression on her face. Pease (2004, p.179) states that when a sideway glance is combined with a lowered eyebrows and a down turned mouth, it shows a suspicious, hostile or a critical attitude. In this scene, the woman's insecurity is reflected through the woman's attitude towards the interviewer, where she does not believe that the interviewer thinks that she is beautiful. Her down turned mouth signifies her sadness when she received a compliment from the interviewer, while her response "I don't know. I don't get called that, that often." shows what makes her doubt what the interviewer said about her. The words "I don't know." shows her uncertainty, as well as low self-esteem that appears because of her conflicting view of herself where she does not consider herself attractive before receiving a compliment. The words "I don't get called that often." combined with her sad expression show that she once dealt with a bad experience that involves her appearance that results in her doubt and low selfesteem. In other words, her statement, combined with other modalities such as her facial expressions and gestures shows her insecurity (Paltridge, 2012, p.169). 
In conclusion to this subchapter, based on Paltridge's idea of multimodal discourse analysis, the writer found out that the reflection of insecurity in this video advertisement is seen through the semiotic resources reflected in people's reaction before and after receiving the interviewer's compliment. Some people's semiotic resources project a neutral expression before receiving a compliment, and some of them shows hesitation, awkwardness, and unhappiness as their reaction to the interviewer's compliment. There are also some people who smile even though they do not consider themselves as an attractive person. They smile to create a happy zone, or an area where they can feel a sense of spontaneous happiness to avoid the fact that they feel insecure about themselves.

\section{The Construction of the Changing Process of Insecurity to Self-acceptance}

The second research question of this research is to find out how the changing process of insecurity to self-acceptance is portrayed is constructed in the video advertisement. The writer began the analysis by finding out how verbal and nonverbal expressions are able to portray the construction of the changing process from of insecurity to self-acceptance in the video.

Facial expression and gesture contribute in creating meaning in this scene. The woman in this scene has appeared in the beginning of the video. In the first scene, the woman is looking straight to the camera with a neutral expression seen on her face. The woman's expression in the first scene serves as semiotic resources that express ambiguity. The ambiguity that she shows signifies her nervousness as a result of being interviewed on camera. In the second scene, the woman can be seen laughing for a brief moment before rubbing her eye with her left hand. Her smile is a form of natural smile because it is generated after she received a compliment from the interviewer. Her natural smile shows that the woman feels at ease after the interviewer reassures her about her beauty. According to Pease, a person who shows a natural smile when that person reacts to other's statement demonstrates that the one who smiles accepts the statement (2004, p.68). In this video advertisement, the fact that a stranger think that she is beautiful makes her touched and moves her to tears. The woman moves to tears because previously, she does not see herself as a beautiful person. Her smile and gestures, that is, rubbing her eyes signifies that she is happy that someone thinks that she is beautiful. The changing process from insecurity to selfacceptance is portrayed in the woman's changing expression from neutral to smiling and moves to tears because of the compliment. The woman's changing expression from neutral facial expression to smiling, and the gestures that she rubs her eyes shows that her opinion about herself changes. At first, she shows her insecurity, but later on, her insecurity transforms into self-acceptance. Although she does not say anything, according to Paltridge, her facial expression, gestures, and postures serve as semiotic resources that produces meaning (2012, p.171).

Similar to the previous scene, facial expression contributes to meaning creation for this scene. Additionally, there is a color difference that are visible to support the interpretation. The woman in this scene has appeared in the beginning of the video where she is seen with a nervous smile. In her second scene, she is smiling widely to the camera with her head slightly titled to her left. There is a significant change of her expression in her second scene. In her first scene, the woman is smiling nervously, while looking straight to the camera. Her gaze, eye contact, and nervous smile reflect her insecurity at the beginning of the video. In the second scene, the woman is smiling widely, showing her teeth to the camera. The color of the scene itself is more vibrant compared to the previous scene. Also, the shot in the second scene appears to be focusing on the woman, resulting in a blurry background. In other words, the scene highlights her confident and natural smile. Her smile, as stated by Pease (2004, p.68), is a form of natural smile. The smile that is seen on her face is generated automatically, right after the interviewer 
mentioned that the purpose of her project is to take pictures that she finds beautiful. In this case, the woman seems to accept the interviewer's idea about her beauty. By using what Paltridge writes, the writer found that in this scene, "the distance of a shot (close vs. medium vs. long), the lighting, color and focus of the shot and the extent to which the image in the shot aims to reflect reality" highlights the woman's natural and confident smile (2012, p.172). It means that the woman shows that she is able to accept the interviewer's opinion that she is beautiful. In this case, the changing process where the woman first feels insecure about herself to the state where she is able to accept herself is reflected through her changing gesture and facial expression which are highlighted by the camera shot.

Facial expressions are able to show the state of emotion of a person at the time. In this scene, the woman can be seen listening to the interviewer intently, with her eyes focusing on the direction of the interviewer. When the interviewer mentioned that she takes pictures of things she finds beautiful the woman smiles and thanks her, and continues with a soft laugh. In the beginning of the scene, a neutral expression can be seen in the woman's face, along with her not breaking her eye contact while the interviewer is explaining the purpose of her project. When looking at the context of the video, which is a form of social experiment, the woman's neutral expression signifies how she feels before the interviewer gives her a compliment; confused and nervous, but tries to compose herself by listening carefully to what the interviewer has to say. After the interviewer gave the woman a compliment through stating the purpose of her project, the woman immediately smiles at her and says "Thank you." to the interviewer before she follows it with a soft laugh. The woman's smile, according to Pease (2004, p.68), is a natural smile because it is formed unconsciously when she receives a compliment. As stated by Paltridge (2012, p.169), meaning is constructed through the combination of words, along with images and sound. The woman's response which is "Thank you." combined with her changing expression from neutral to smiling and laughing show how she appreciates the compliment from the interviewer. In other words, the changing process from insecurity to self-acceptance is reflected through the woman's changing facial expression and her response to the compliment.

The change of attitude and facial expression are able to reveal meaning, which are portrayed in the next scene where the woman is seen in another scene with a faint smile and her ability to see herself differently. The woman in this scene has appeared before in near middle part of the video. There are notable changes in the woman's expression in this scene. In the first scene the woman appears to be responding to the interviewer with lack of eye contact and a sad expression on her face that is indicated by her gaze and her down turned mouth. Her statement the first scene and her sad expression reflect her insecurity in the first scene. However, in the second scene, the woman is no longer seen with a sad expression on her face. Instead, she forms a faint smile as she responds to the interviewer, along with more eye contact compared to the first scene. Also, the woman's verbal response shows a more positive attitude towards herself, compared to her first response. Her response which says that she is now able to accept her quirks, and realizing how differences is what makes people beautiful, shows how she is able to accept the interviewer's compliment, as well changing her perspective about beauty among individual. The change in her facial expression and the words she uses to respond to the interviewer, as semiotic resources (Paltridge, 2012, p.169), show the changing process from the first encounter where she feels insecure about her appearance to the part where she is able to love her own quirks.

Following the previous scenes, facial expression and choice of words in this scene are able to reveal the meaning of the nonverbal expressions. In this scene, the woman is seen responding to the interviewer's compliment by showing her part of body which makes her feel insecure; her under eyes. She traces her fingers along her under eyes as she responds before ending it with a laugh. Her gesture which is showing her under eyes shows how she acknowledges what makes her insecure, yet still able to respond to the interviewer openly with a laugh. Her openness 
towards the interviewer shows how she is comfortable with the interviewer and does not find the interviewer's compliment as something insulting. How the woman acknowledges her flaws by using gesture shown to the interviewer, and how she responds cheerfully implies how the woman is able to accept herself even though she feels insecure about her appearance before. Her facial expression, gestures, and words in her response, which according to Paltridge are the semiotic resources, show the changing process from insecurity to self-acceptance (2012, p.171).

In conclusion, the writer found that people's reaction mostly consists of surprised smile and laughter, in which case, are generated automatically when they receive a compliment from the interviewer. The compliment that they receive serves as a signal to their brain that cause them to smile naturally in response to the pleasure of being complimented by others. The changing process is seen through the way the people are surprised to receive a compliment, but also happy at the same time.

\section{CONCLUSION}

In this research, I find that an advertisement consists of both verbal and nonverbal expressions. In this case, the verbal expressions in the advertisement are supported by the nonverbal expressions in order that the viewer or audience are able to understand the message it delivers. In this thesis, I analyze how Samsung use verbal and nonverbal expressions in its advertisement of Galaxy A8 smartphone for communicating a message. To reveal the intended message, I use the theory of multimodal discourse analysis by Brian Paltridge to find out how verbal and nonverbal expressions such as words, images, colors, sounds, and gestures in the video advertisement are able to reveal how Samsung portrays the issue of insecurity and selfacceptance through their advertisement. In addition, I use the theory of body language by Allan and Barbara Pease to support my interpretation of the nonverbal expressions of the interviewees such as facial expression, eye contact, and gesture.

From the analysis of this advertisement, I find that this advertisement focuses on delivering a message to its viewers instead of promoting its product. Samsung intends to gives a message to the viewers that self-love is important. This message is expressed throughout the video advertisement. The interviewer, in each scene, begins the interview by mentioning the purpose of the project which is taking picture of thing she finds beautiful. The purpose of the project is always mentioned to the interviewees at the beginning as the introductory phrase which shows the main message of self-love that Samsung intends to deliver to its viewers. The interviewees' reaction of the compliment from the interviewer, reflects the insecurity, as well as the changing process from insecurity to self-acceptance. There are some people who responds to the compliment with hesitation, awkward smiles, and unhappiness. There are also interviewees who respond to the compliment by laughing to hide their insecurity. The changing process from insecurity to self-acceptance is shown in some parts where interviewees respond to the compliment differently. The reaction triggered by the compliment in this part mostly consists of surprised smile and laughter. The smile and laughter are triggered automatically when they receive a compliment from the interviewer who is a stranger to the interviewees.

Based on the form of the advertisement, which is a social experiment, I find that the advertisement is both unique and eye-opening. This advertisement is unique because it does not promote the smartphone directly. The advertisement focuses on the message that Samsung would like to deliver, and the smartphone is merely a tool to help the advertiser to capture the beauty of each interviewee. The advertisement of Samsung Galaxy A8 is eye-opening because it contains an important message for the viewers. The message that Samsung intends to deliver is that it is important to embrace our true selves, which is often hard at present times where people constantly trying to become someone else. In short, Samsung is a company who encourages self-love to people around the world. 


\section{REFERENCES}

Davies, J. (2011). Discourse and computer-mediated communication. In B. Paltridge, \& K. Hyland, The continuum companion to discourse analysis (pp. 228-243). New York: Continuum International Publishing Group.

Harris, R. J. (2004). Types of ads. In R. J. Harris, A cognitive psychology of mass communication (p. 98). Mahwah: Lawrence Erlbaum Associates, Inc., Publishers.

Harris, R. J. (2004). Emotional appeals. In R. J. Harris, A cognitive psychology of mass communication (p. 99). Mahwah: Lawrence Erlbaum Associates, Inc., Publishers.

O'Halloran, K. L. (2011). Multimodal discourse analysis. In B. Paltridge, \& K. Hyland, The continuum companion to discourse analysis (pp. 120-137). New York: Continuum International Publishing Group.

Paltridge, B. (2012). Background to multimodal discourse analysis. In B. Paltridge, Discourse analysis an introduction (pp. 170-171). London: Bloomsbury Publishing Plc.

Paltridge, B. (2012). Examples of multimodal discourse analysis. In B. Paltridge, Discourse analysis an introduction (p. 172). London: Bloomsbury Publishing Plc.

Paltridge, B. (2012). Genre, speech acts and multimodality. In B. Paltridge, Discourse analysis an introduction (p. 177). London: Bloomsbury Publishing Plc.

Pease, A., \& Pease, B. (2004). Eye signals. In A. Pease, \& B. Pease, The definitive book of body language (pp. 165-179). Buderim: Pease International.

Pease, A., \& Pease, B. (2004). How body language reveals emotions and thoughts. In A. Pease, \& B. Pease, The definitive book of body language (p. 11). Buderim: Pease International.

Pease, A., \& Pease, B. (2004). The magic of smiles and laughter. In A. Pease, \& B. Pease, The definitive book of body language (pp. 67-70). Buderim: Pease International.

Schreier, M. (2012). Qualitative content analysis in practice. London: SAGE Publications Ltd.

ThinkMarketing. (2018, January 14). Samsung A8 social experiment proves that everyone is beautiful. Retrieved from https://thinkmarketingmagazine.com/samsung-a8-usesmoving-viral-video-inspiration/ 